\title{
Does the Vulnerable sun bear Helarctos malayanus damage crops and threaten people in oil palm plantations?
}

\author{
Roshan Guharajan, Nicola K. Abram, Mohd Azzumar Magguna \\ Benoit Goossens, Siew Te Wong, Senthilvel K. S. S. Nathan and \\ DAVID L. GARSHELIS
}

\begin{abstract}
Largely as a result of the expansion of oil palm Elaeis guineensis, forest fragmentation has occurred on a large scale in Borneo. There is much concern about how forest-dependent species, such as the Vulnerable sun bear Helarctos malayanus, can persist in this landscape. The absence of sufficient natural food in forest fragments could drive sun bears into oil palm plantations, where they risk coming into conflict with people. We interviewed oil palm plantation workers and farmers in the Lower Kinabatangan region of Sabah, Malaysian Borneo, to ascertain if sun bears were utilizing plantations, if they were causing damage to the crop, and how the bears were perceived by people. To obtain a comparative baseline we extended these questions to include other species as well. We found that bears were rarely encountered in plantations and were not considered to be destructive to the oil palm crop, although they were generally feared. Other species, such as macaques Macaca spp., bearded pigs Sus barbatus, and elephants Elephas maximus, had more destructive feeding habits. Sun bears could use this readily available food resource without being targeted for retribution, although incidental human-related mortality remains a risk. Although bears could gain some
\end{abstract}

Roshan Guharajan* (Corresponding author) and David L. Garshelis $\dagger$ Department of Fisheries, Wildlife and Conservation Biology, University of Minnesota, 135 Skok Hall, 2003 Upper Buford Circle, St. Paul, Minnesota 55108, USA. E-mail roshang88@gmail.com

Nicola K. Aвram Living Landscape Alliance, Kota Kinabalu, Sabah, Malaysia; and ARC Centre of Excellence for Environmental Decisions, University of Queensland, Brisbane, Australia and Forever Sabah, Kota Kinabalu, Sabah, Malaysia

Mohd Azzumar Magguna and Benoit Goossensł Danau Girang Field Centre, Kota Kinabalu, Sabah, Malaysia

Siew Te Wong Bornean Sun Bear Conservation Centre, Sandakan, Sabah, Malaysia

Senthilvel K.S.S. Nathan Sabah Wildlife Department, Kota Kinabalu, Sabah, Malaysia

${ }^{*}$ Current address: Leibniz Institute for Zoo and Wildlife Research, AlfredKowalke-Str. 17, 10315 Berlin, Germany

$\dagger$ Also at: Minnesota Department of Natural Resources, Grand Rapids, Minnesota, USA

¥Also at: School of Biosciences, Cardiff University, Cardiff, UK; Sustainable Places Research Institute, Cardiff University, Cardiff, UK; and Sabah Wildlife Department, Kota Kinabalu, Sabah, Malaysia

Received 3 January 2017. Revision requested 24 March 2017.

Accepted 26 June 2017. First published online 4 December 2017. nutritional benefit from oil palm, plantations do not provide the diversity of food and cover available in a natural forest.

Keywords Borneo, crop damage, Helarctos malayanus, human-wildlife conflict, Lower Kinabatangan, mortality risk, oil palm, Sabah

Supplementary material for this article can be found at https://doi.org/10.1017/So030605317001089

\section{Introduction}

alaysia is the second largest grower of oil palm Elaeis 1 guineensis (U.S. Department of Agriculture, Foreign Agricultural Service, 2017). However, the expansion of the industry has had serious implications: during 1995-2005, $55-59 \%$ of Malaysian oil palm plantations were established through forest conversion (Koh \& Wilcove, 2008), and oil palm agriculture has adverse impacts on biodiversity (Yue et al., 2015; Vijay et al., 2016). Wildlife that enter plantations are at risk of being hunted, or subject to retribution for damaging crops (Meijaard et al., 2011; Azhar et al., 2014; Luskin et al., 2014). Oil palm plantations can be nutritionally poor for some species, such as orang-utans Pongo spp. (Campbell-Smith et al., 2011), whereas others utilize the abundance of palm fruits and rodents as prey (Rajaratnam et al., 2007; Nakashima et al., 2013). Certain species can use oil palm landscapes as corridors (Campbell-Smith et al., 2011; Estes et al., 2012) and feeding and resting sites (Nakashima et al., 2013; Ancrenaz et al., 2015).

Borneo is a stronghold for the sun bear Helarctos malayanus (Augeri, 2005), which is categorized as Vulnerable on the IUCN Red List (Fredriksson et al., 2008). Previous research on Borneo showed that sun bears are sensitive to extreme variation in supra-annual mast fruiting events, with some bears starving during long inter-mast periods (Wong et al., 2005; Fredriksson et al., 2007) and others using croplands to supplement their diet (Fredriksson, 2005; Cheah, 2013). With oil palm plantations now bordering many forests in Borneo, this crop could, to some degree, be a potential supplementary food source for bears, especially during periods of low natural food availability. However, increased reliance on agricultural products for food often comes with 
the risk of conflict and persecution (Fredriksson, 2005; Liu et al., 2011; Scotson et al., 2014).

Interview surveys have been used successfully to gauge perceptions and attitudes towards wildlife in oil palm plantations (Azhar et al., 2014; Luskin et al., 2014; Ancrenaz et al., 2015). We used interview surveys to understand the use of plantations by sun bears, whether their feeding damaged crops, and whether people perceived them as a threat. We hypothesized that conversion of forest to oil palm would force sun bears to use this resource more, compounding retaliation against them. We collected information on multiple species for comparison with sun bears.

\section{Study area}

Our study area was the Lower Kinabatangan floodplain in Sabah, Malaysian Borneo (Fig. 1). The original forest landscape has been altered by logging and agriculture, beginning in the 1950 (Azmi, 1998), leaving degraded, fragmented forest surrounded by oil palm. Most of the remaining forest (c. 45,000 ha) lies within the Lower Kinabatangan Wildlife Sanctuary and several forest reserves. Forest types in the floodplain include mangrove forest, Nypa fruticans swamp, freshwater swamp forest, peat swamp forest, and mixed dipterocarp forest (Abram et al., 2014). Besides the sun bear, prominent wildlife species include the Bornean orang-utan Pongo pygmaeus, the Bornean elephant Elephas maximus borneensis and the Sunda clouded leopard Neofelis diardi.

\section{Methods}

\section{Data collection}

We interviewed 117 respondents from oil palm plantations in June 2013 and during May-October 2014, within a section of the Lower Kinabatangan (Fig. 1). We sampled plantations where we gained permission: 10 oil palm estates (hereafter estates) and 17 small farms (known as kebun). In estates we interviewed the operations staff, whereas in kebun we spoke to the farmers themselves. We obtained information on the total planted area (hereafter plantation size), the presence of immature and mature palms (mature $>3$ years old), and whether the plantation bordered forest (hereafter border). We asked respondents their age (hereafter age) and how long they had worked in the plantation (hereafter time, in four categories: $<1$ year, $1-5$ years, $6-10$ years, $>10$ years).

We asked respondents to identify wildlife encountered in plantations (mammals and certain reptiles), using reference images of protected species in Sabah (Sabah Wildlife Department, 1997; WWF-Malaysia, 2013). We did not include birds, squirrels or monitor lizards Varanus spp., but recorded these when respondents provided information on them. We asked respondents to rate how often they saw specific species (rarely or commonly; we did not provide guidance on these terms), where they saw them (within plantation, plantation-forest border, and/or secondary forest within plantations) and at what time the encounter(s) took place (morning, afternoon and/or night).

We asked whether the observed species fed on loose palm fruits that had fallen to the ground (hereafter loose fruits), harvested fruit bunches on the ground (hereafter fruit bunches), fruits on the palms (hereafter palm fruits), and/ or oil palm shoots (hereafter palm shoots). We asked respondents to identify species that were destructive (yes or no) towards oil palms as a result of their feeding habits.

We also asked whether each species was considered to be dangerous (yes or no); if the respondent answered yes, we asked them to rate this qualitatively (least dangerous, dangerous, or extremely dangerous). We asked respondents to provide details of their reaction to encounters with dangerous species: did they retreat, chase the animal away, capture it and/or kill it? We ended each interview by asking respondents how they felt about hunting and protecting wildlife. These questions were asked towards the end to minimize any bias in reporting.

\section{Data analysis}

We conducted all analyses in $R$ 3.2.2 (R Development Core Team, 2015). For examination of wildlife encounters we grouped seven species into three groups: macaques (Macaca fascicularis, M. nemestrina), snakes (Naja sumatrana, Python reticulatus, Python breitensteini), and civets (Viverra tangalunga, Paradoxurus hermaphroditus). We excluded squirrels, birds and monitor lizards from all summaries and analyses regarding wildlife encounters. For the purpose of ranking we calculated the mean commonness $(1=$ rare, $2=$ common $)$, destructiveness $(\mathrm{o}=$ yes, $1=$ no), and perceived danger level ( $\mathrm{o}=$ not dangerous, $1=$ least dangerous, $2=$ dangerous, 3 = extremely dangerous) of each species (Marchal \& Hill, 2009). We did not include non-answers in these calculations because we assumed if respondents did not answer, it meant they had no opinion.

We then separated all species into two groups based on body size, as we predicted larger species might be perceived as being more destructive and dangerous, as well as more visible. One group included all large-bodied mammals $\left(>_{15} \mathrm{~kg}\right.$; hereafter large mammals); the other group included smallerbodied mammals and snakes (hereafter small wildlife). We summed the number of species in each group per respondent.

We fit Poisson generalized linear models with the total count of small wildlife or large mammals encountered per respondent as the response. We included the binary variables border, immature and mature palms, the categorical variable plantation type, and the continuous variable 


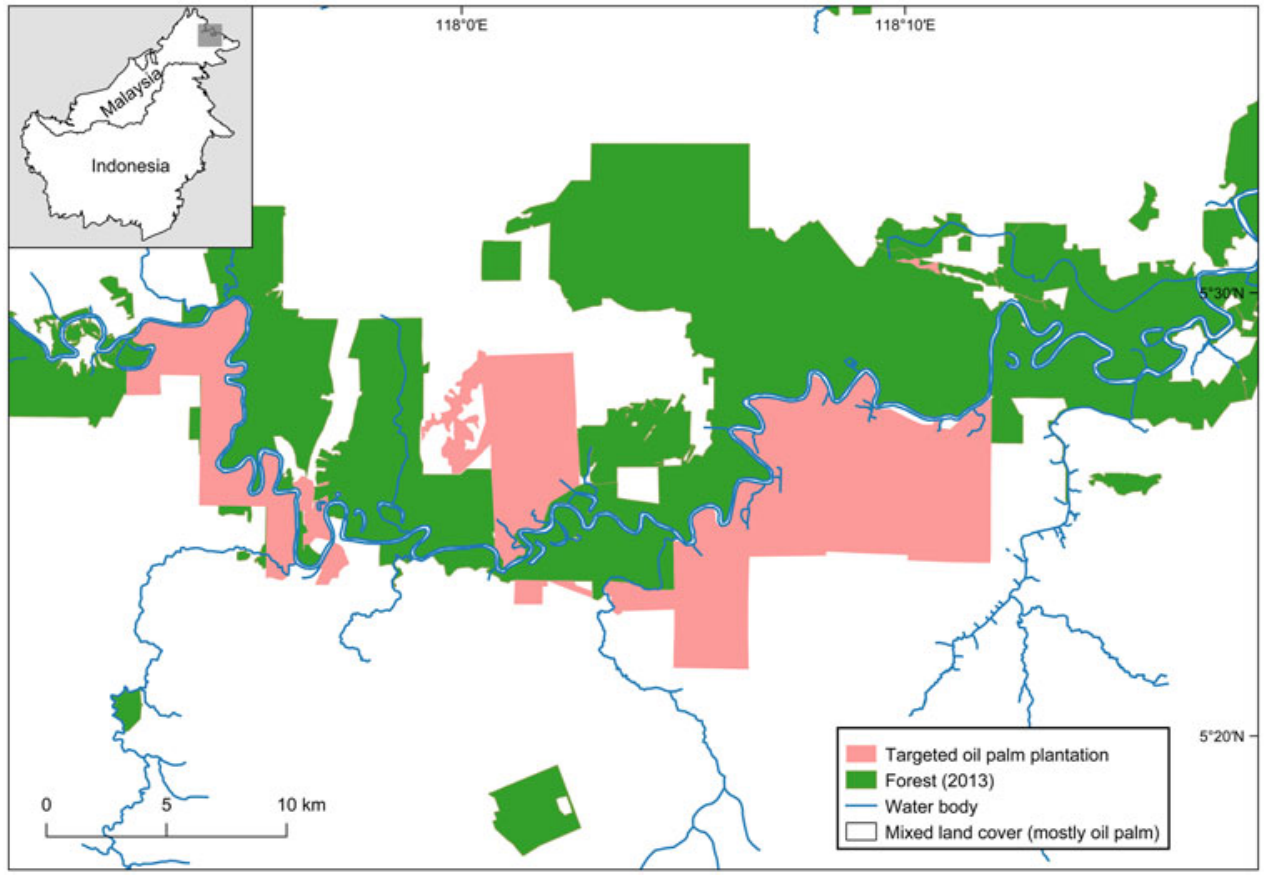

FIG. 1 Locations of oil palm plantations targeted for interviews in the Lower Kinabatangan, Sabah, Malaysian Borneo. plantation size as plantation-level predictors. We also included the categorical variable time and the continuous variable age as respondent-level predictors. We began by fitting single covariate models and subsequently adding predictors that were present in models with the lowest Akaike information criterion corrected for small sample sizes $(\Delta \mathrm{AICc}<2)$ in each successive step. We selected top-ranked models based on AICc and model weights, ignoring competing models with only one additional variable to a better ranked model (Arnold, 2010). We checked all top-ranked models for overdispersion by dividing model residual deviance by degrees of freedom. We assessed multicollinearity between model predictors using generalized variance inflation factor values. We judged model fit visually by plotting residuals against fitted values. As respondents from the same plantation might have had correlated observations, we further fit Poisson generalized linear mixed models with plantation as the random intercept. We compared the generalized linear model and generalized linear mixed model coefficients and 95\% confidence intervals.

For all analyses regarding wildlife feeding habits we included observations of birds and squirrels, as the goal was to understand food resource use and perceived destructiveness. We removed observations that solely involved secondhand information received by respondents about depredations. To model the effects of feeding behaviours and plantation characteristics on destructiveness, we fit binomial generalized linear models with destructive behaviour as the binary response variable, and the binary predictor variables loose fruits, fruit bunches, palm fruits, palm shoots, immature and mature palms. We also included plantation type as a categorical predictor variable. We selected models and checked for multicollinearity in the same way as for the Poisson generalized linear models. We assessed model fit by visually inspecting binned residual versus fitted plots. We calculated area under the receiver operating characteristics curve to discern model predictive power. We fit a binomial generalized linear mixed model to compare model coefficients and 95\% confidence intervals with the generalized linear model.

\section{Results}

Estates $(\mathrm{n}=10, \bar{x}$ mean area $=1,389 \pm \mathrm{SD} 766.6 \mathrm{ha})$ were much larger than kebun $(\mathrm{n}=17, \bar{x}$ mean area $=3 \pm$ SD $1.7 \mathrm{ha})$. Most plantations (77.8\%) had only mature palms, $7.4 \%$ had only immature palms, and $14.8 \%$ had a combination of both. Most respondents $(45.8 \%)$ had worked in their plantation for $>10$ years; $16.1 \%$ had worked for $6-10$ years, $26.3 \%$ for 1-5 years, and $9.3 \%$ for $<1$ year. Most respondents felt that protecting wildlife was necessary (93.2\%). Some (29.7\%) felt that they should be allowed to hunt, but a larger number (64.4\%) felt this was not necessary (the rest did not answer). More than half the respondents (53.7\%) felt they should be allowed to keep wildlife as pets.

Respondents encountered at least 25 species (Table 1 ). Most (57\%) encounters occurred within the oil palm plantation, with another $40.8 \%$ occurring at the border of forest and plantation, and $\mathbf{2 . 2} \%$ in secondary forest patches. Encounters often took place in the morning (42.5\%), but also in the afternoon (34\%) and at night (23.5\%). Respondents rarely encountered sun bears within plantations (Table 1). Sun bears were encountered somewhat more commonly than clouded leopards and Sunda 
TABLE 1 Mean \pm SD commonness ranks, with the total number of records of mammals and reptiles encountered by respondents $(n=117)$ from oil palm plantations in the Lower Kinabatangan, Sabah, Malaysia (Fig. 1), and the number of records in which respondents were able to rank the species.

\begin{tabular}{|c|c|c|c|}
\hline Species & $\begin{array}{l}\text { Mean } \pm \text { SD } \\
\text { commonness rank }^{1}\end{array}$ & $\begin{array}{l}\text { Total no. } \\
\text { of records }\end{array}$ & $\begin{array}{l}\text { No. of } \\
\text { ranked records }^{2}\end{array}$ \\
\hline Sunda clouded leopard Neofelis diardi & $1.00 \pm 0.00$ & 2 & 2 \\
\hline Sunda pangolin Manis javanica & $1.05 \pm 0.22$ & 27 & 21 \\
\hline Muntjac Muntiacus sp. & $1.09 \pm 0.30$ & 13 & 11 \\
\hline Sambar Rusa unicolor & $1.17 \pm 0.38$ & 32 & 30 \\
\hline Sun bear Helarctos malayanus & $1.25 \pm 0.46$ & 8 & 8 \\
\hline Porcupine Hystrix sp. & $1.29 \pm 0.46$ & 40 & 38 \\
\hline Malay badger Mydaus javanensis & $1.31 \pm 0.47$ & 29 & 29 \\
\hline Mousedeer Tragulus sp. & $1.31 \pm 0.48$ & 16 & 16 \\
\hline Western tarsier Tarsius bancanus & $1.33 \pm 0.52$ & 6 & 6 \\
\hline Bornean elephant Elephas maximus borneensis & $1.33 \pm 0.47$ & 57 & 52 \\
\hline Bornean orang-utan Pongo pygmaeus & $1.34 \pm 0.48$ & 52 & 50 \\
\hline Proboscis monkey Nasalis larvatus & $1.38 \pm 0.49$ & 32 & 29 \\
\hline Slow loris Nycticebus sp. & $1.40 \pm 0.55$ & 6 & 5 \\
\hline Müller's Bornean gibbon Hylobates muelleri & $1.47 \pm 0.52$ & 16 & 15 \\
\hline Smooth-coated otter Lutrogale perspicillata & $1.48 \pm 0.50$ & 49 & 48 \\
\hline Snakes Python spp., Naja sumatrana & $1.48 \pm 0.50$ & 133 & 125 \\
\hline Colugo Galeopterus variegatus & $1.50 \pm 0.71$ & 2 & 2 \\
\hline Leopard cat Prionailurus bengalensis & $1.58 \pm 0.50$ & 38 & 36 \\
\hline Civets Viverra tangalunga, Paradoxurus hermaphroditus & $1.59 \pm 0.50$ & 84 & 80 \\
\hline Estuarine crocodile Crocodylus porosus & $1.60 \pm 0.52$ & 11 & 10 \\
\hline Bearded pig Sus barbatus & $1.77 \pm 0.42$ & 98 & 96 \\
\hline Macaque Macaca spp. & $1.94 \pm 0.23$ & 151 & 144 \\
\hline
\end{tabular}

${ }^{1}$ Ranks: 1, rarely encountered; 2, commonly encountered.

${ }^{2}$ This number was used in the calculation of the mean commonness rank.

pangolins Manis javanica, but less commonly than elephants and orang-utans. The most commonly reported species were macaques, bearded pigs Sus barbatus, civets and leopard cats Prionailurus bengalensis.

The top-ranked Poisson generalized linear models $(\Delta \mathrm{AICc}<2)$ for encounters with small wildlife contained the predictors age, immature palms, border and time (Table 2). For large mammals, top-ranked models $(\triangle \mathrm{AICc}<2)$ contained the same predictors, along with mature palms (Table 3). Overdispersion parameters for all models were $<1.5$, supporting use of the Poisson distribution. Generalized variance inflation factor values were $<_{3}$, indicating that multicollinearity between predictors was not significant. Residuals versus fitted plots displayed good fits. The generalized linear mixed model for small wildlife failed to converge, and there was no variation between the random components $(\mathrm{SD}=0)$ of the large mammal generalized linear mixed model.

Respondents $(n=104)$ identified eight species (excluding squirrels and birds) that fed on loose palm fruits, four that fed on harvested fruit bunches, and eight that fed on fruits still on the palm (Fig. 2). Only one respondent reported sun bears depredating oil palm fruits, and said they climbed the palms to feed. Respondents identified another seven species that fed on palm shoots, including two respondents who said this was true of sun bears (Fig. 2). Respondents identified these feeding habits based on visual observations (74.5\%), feeding signs (21.5\%) and information received from others (4\%). No respondent could describe or show us any feeding sign by sun bears.

Respondents considered nine species to be destructive to the oil palm crop but there was considerable variation among these in terms of perceived destructiveness (Fig. 3). Compared to macaques, pigs and elephants, sun bears caused little damage (Table $\mathrm{S}_{1}$ ). Model selection for the binomial generalized linear models identified top-ranked models that all contained palm shoots as a predictor of destructive behaviour $(\triangle \mathrm{AICc}<2$; Table 4$)$. Other variables included in the top-ranked models were plantation type and bunch. Generalized variance inflation factor values suggested that multicollinearity was not significant. Binned residual versus fitted plots displayed a good fit. Area under the curve for all models was $0.6-0.7$, indicating adequate predictive power. The binomial generalized linear mixed model failed to converge.

Eight species were considered to be dangerous $(n=84$ respondents; Table 5). Among these, clouded leopards and estuarine crocodiles Crocodylus porosus were considered to be most dangerous. Sun bears were perceived to be as dangerous as orang-utans. Respondents could recount only one 
TABLE 2 Top-ranked models $(\Delta \mathrm{AICc}<2)$ for small wildlife (small-bodied mammals and snakes) encountered by respondents from oil palm plantations in the Lower Kinabatangan, Sabah, Malaysia (Fig. 1), with number of parameters ( $k$ ), $\log$ likelihood, Akaike’s information criterion adjusted for small sample sizes (AICc), change in $\mathrm{AICc}\left(\Delta \mathrm{AIC}_{\mathrm{c}}\right)$, and Akaike weight.

\begin{tabular}{|c|c|c|c|c|c|}
\hline Model $^{1}$ & $k$ & Log likelihood & $\mathrm{AICc}$ & $\Delta \mathrm{AICc}$ & Akaike weight \\
\hline Immature + Border + Age & 4 & -259.07 & 526.51 & 0.00 & 0.24 \\
\hline Immature + Mature + Border + Age $^{2}$ & 5 & -258.24 & 527.03 & 0.52 & 0.18 \\
\hline Immature + Type + Border + Age $^{2}$ & 5 & -258.56 & 527.67 & 1.16 & 0.13 \\
\hline Immature + Border + Age + Size $^{2}$ & 5 & -258.62 & 527.79 & 1.29 & 0.12 \\
\hline Immature + Border + Time & 6 & -257.55 & 527.88 & 1.37 & 0.12 \\
\hline Immature + Border & 3 & -260.85 & 527.93 & 1.42 & 0.12 \\
\hline Immature + Mature + Border $^{2}$ & 4 & -260.06 & 528.49 & 1.99 & 0.09 \\
\hline Intercept only & 1 & -270.34 & 542.71 & 16.21 & 0.00 \\
\hline
\end{tabular}

${ }^{1}$ Immature, oil palms < 3 years of age; Mature, oil palms $>3$ years of age; Type, plantation type; Border, bordering intact forest; Age, respondent age; Size, total planted area; Time, length of time respondent worked in plantation.

${ }^{2}$ Models with an additional parameter within $\triangle \mathrm{AICc} \leq 2$ of an otherwise similar better-ranked model were not considered to be competitive despite having strong support. The extra parameter represents noise and thus does not necessarily infer biological significance.

TABLE 3 Top-ranked models $(\Delta \mathrm{AICc}<2)$ for large mammals encountered by respondents from oil palm plantations in the Lower Kinabatangan, Sabah, Malaysia (Fig. 1), with number of parameters ( $k$ ), log likelihood, Akaike's information criterion adjusted for small sample sizes (AICc), change in $\operatorname{AICc}\left(\Delta \mathrm{AIC}_{\mathrm{c}}\right)$, and Akaike weight.

\begin{tabular}{llllll}
\hline Model $^{1}$ & $K$ & Log likelihood & AICc & $\Delta$ AICc & Akaike weight \\
\hline Immature + Mature + Border + Age & 5 & -202.98 & 416.52 & 0.00 & 0.33 \\
Immature + Border + Age & 4 & -204.27 & 416.91 & 0.39 & 0.27 \\
Immature + Mature + Border + Age + Size $^{2}$ & 6 & -202.72 & 418.22 & 1.70 & 0.14 \\
Immature + Mature + Age $_{\text {Immature + Type + Border + Age }}^{2}$ & 4 & -204.97 & 418.31 & 1.79 & 0.13 \\
Intercept only $^{2}$ & 5 & -203.98 & 418.51 & 1.99 & 0.12 \\
\hline
\end{tabular}

${ }^{1}$ Immature, oil palms $<3$ years of age; Mature, oil palms $>3$ years of age; Type, plantation type; Border, bordering intact forest; Age, respondent age; Size, total planted area.

${ }^{2}$ Models with an additional parameter within $\Delta \mathrm{AICc} \leq 2$ of an otherwise similar better-ranked model were not considered to be competitive despite having strong support. The extra parameter represents noise and thus does not necessarily infer biological significance.

mauling by a clouded leopard and three by sun bears. Most respondents said they would retreat from a dangerous animal (58.3\%), but $34.6 \%$ said they would sometimes chase the animal away. Very few admitted that they would capture $(1.9 \%)$ or kill $(5.1 \%)$ a dangerous animal.

\section{Discussion}

Macaques and bearded pigs were the most commonly encountered species, successfully utilizing the oil palm landscape. Snakes, leopard cats and civets were also commonly encountered, attracted by the abundance of rodent prey (Rajaratnam et al., 2007). Sun bears, however, were rarely encountered, which suggests either avoidance of plantations or elusive behaviour by the species.

Respondents from plantations containing immature oil palms encountered more species. Wildlife may be more visible in these plantations, and the palms readily consumed. Encounters with large mammals were associated with palms of both age classes, suggesting that cover was attractive to them. Respondents encountered more species in plantations bordering forest, which probably serves as a refuge (Rajaratnam et al., 2007; Nakashima et al., 2013); for example, although radio-collared sun bears ventured into oil palm plantations far $(>4 \mathrm{~km})$ from forest, they retreated to cover during daylight (Normua et al., 2004; Cheah, 2013).

Older respondents encountered more species, probably because they had worked for longer at the plantation. We found a positive association between years in a plantation and the number of small wildlife species encountered.

Elephants, porcupines Hystrix sp., macaques and bearded pigs were all perceived to be particularly destructive of oil palm crops, in line with results from other studies (Sabah Wildlife Department, 2010; Azhar et al., 2014; Luskin et al., 2014). These species fed on palm shoots, a strong indicator of destructive feeding. Young palms are particularly at risk as the shoot is exposed and the palm easily destroyed. Sun bears also apparently fed on palm shoots, but rarely compared to other species (Fig. 2). Feeding on fruit bunches was also considered to be destructive. Bunches were mainly consumed by bearded pigs and macaques, both abundant and occurring in large groups. Ripe fruit bunches are destined for oil palm mills, making any 
(a) Loose fruits

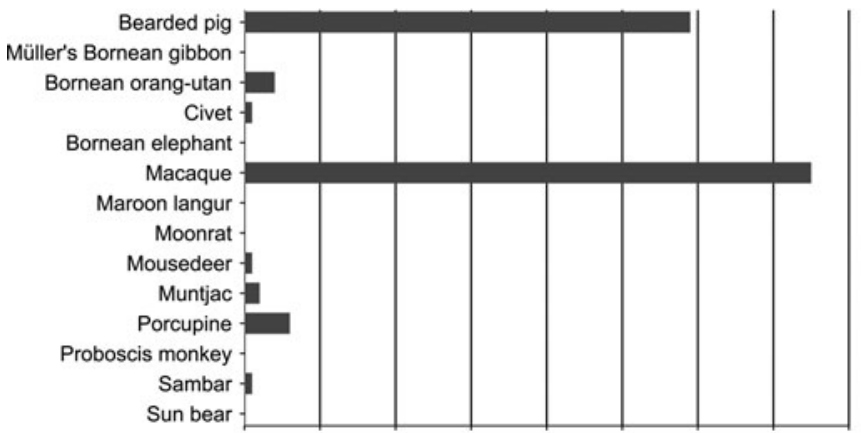

(c) Palm fruits

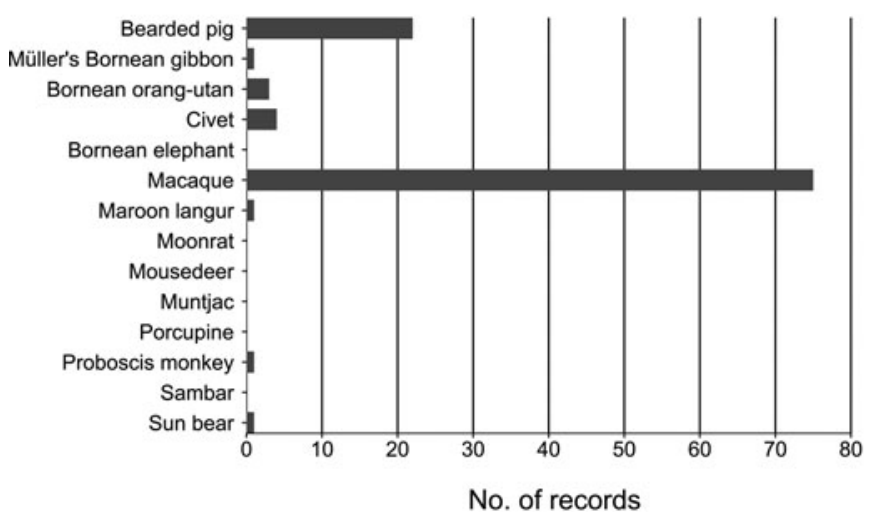

(b) Fruit bunches

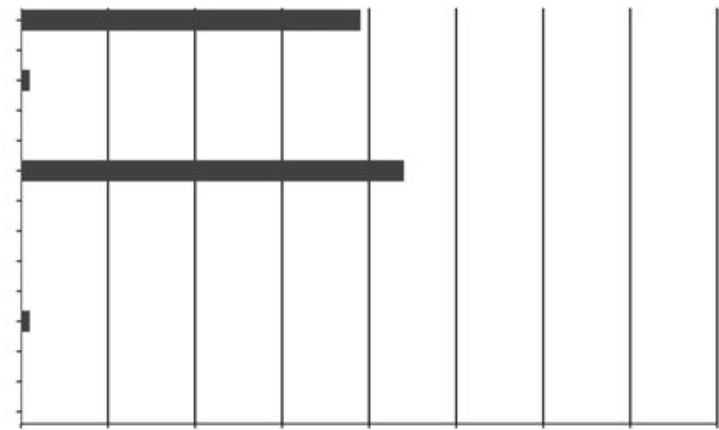

(d) Palm shoots

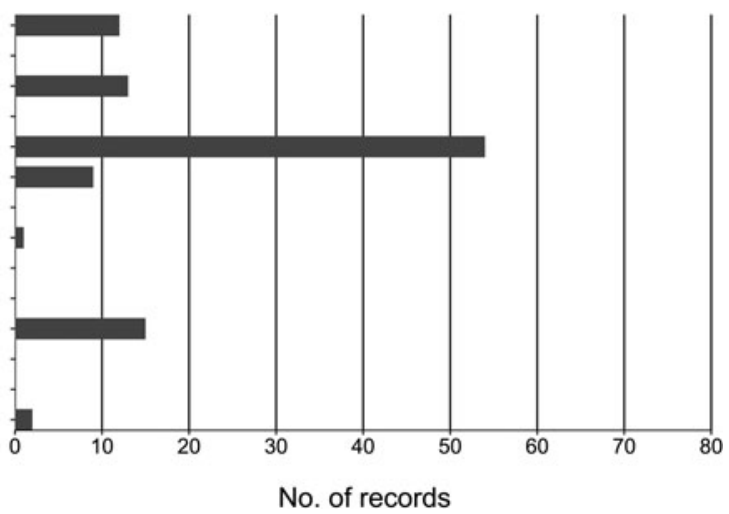

FIG. 2 Records of wildlife species feeding on (a) loose fruits scattered on the ground, (b) harvested fruit bunches on the ground, (c) fruits on the palm tree, and (d) oil palm shoots, as reported by respondents $(n=104)$ from oil palm plantations in the Lower Kinabatangan, Sabah, Malaysian Borneo (Fig. 1).

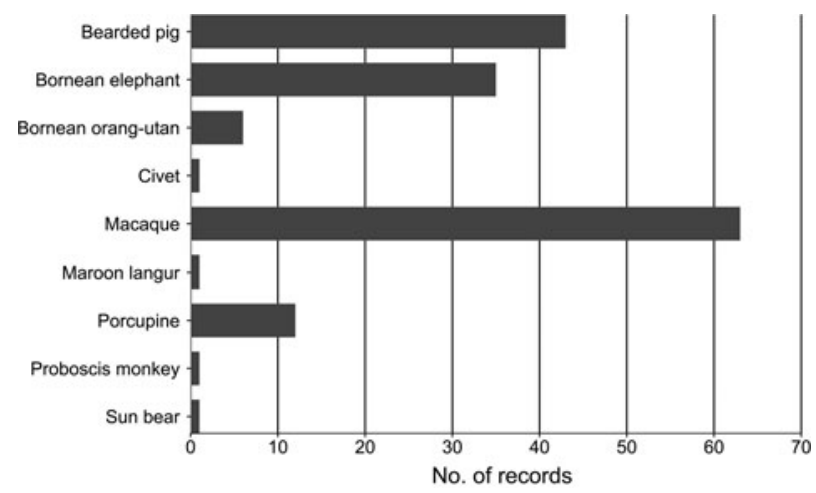

FIG. 3 Wildlife species considered to be destructive to the oil palm crop according to respondents $(n=74)$ from oil palm plantations in the Lower Kinabatangan, Sabah, Malaysian Borneo (Fig. 1).

loss highly undesirable. Kebun respondents were more apt to perceive wildlife as being destructive, probably because of their limited yield and lack of resources to mitigate crop depredation.

Three species ranked highly in terms of both destructiveness and danger: elephants, macaques and bearded pigs (Fig. 4). Among these, elephants are at the forefront of human-wildlife conflict in Sabah (Sabah Wildlife Department, 2010), and now also in adjacent Kalimantan, Indonesia (Suba et al., 2017). Sun bears were considered to be negligibly destructive but were often feared, although only a few attacks were reported. In other parts of their range, attacks by sun bears are reportedly more common (Sethy \& Chauhan, 2013).

We were surprised that respondents tended not to view bears as being destructive to oil palms, as other studies have found them to be destructive to many other crops, as evidenced by conspicuous feeding sign and damage (Fredriksson, 2005; Sethy \& Chauhan, 2013; Scotson et al., 2014; Wong et al., 2015). We suspect that the bears fed largely on loose fruits and fruit bunches (Plate 1), which would cause little visible damage and leave no definitive evidence of their presence (Fig. 2). We knew of a sun bear feeding in a plantation but we could not find any feeding sign; however, we found abundant fresh sign (claw marks on trees) in neighbouring forest. Camera-trapped sun bears in forest adjacent to plantations were active mainly during crepuscular and nocturnal hours, when human presence is minimal ( $R$. Guharajan et al., unpubl. data), which explains why few respondents saw them. Sun bears are known to become more nocturnal when feeding on crops (Normua et al., 2004; Sethy 
TABLE 4 Top-ranked models for wildlife destructiveness in oil palm plantations in the Lower Kinabatangan, Sabah, Malaysia (Fig. 1), with number of parameters $(k), \log$ likelihood, Akaike's information criterion adjusted for small sample sizes (AICc), change in AICc ( $\triangle \mathrm{AICc}$ ), and Akaike weight.

\begin{tabular}{|c|c|c|c|c|c|}
\hline Model $^{1}$ & $k$ & Log likelihood & $\mathrm{AICc}$ & $\Delta \mathrm{AICc}$ & Akaike weight \\
\hline Bunch + Type + Shoot & 4 & -137.11 & 282.40 & 0.00 & 0.24 \\
\hline Type + Shoot & 3 & -138.38 & 282.87 & 0.47 & 0.19 \\
\hline Bunch + Type + Mature + Shoot $^{2}$ & 5 & -136.88 & 284.04 & 1.63 & 0.10 \\
\hline Type + Mature + Shoot $^{2}$ & 4 & -138.00 & 284.20 & 1.79 & 0.10 \\
\hline Bunch + Type + Palm + Shoot $^{2}$ & 5 & -136.97 & 284.22 & 1.81 & 0.10 \\
\hline Bunch + Immature + Type + Shoot $^{2}$ & 5 & -136.97 & 284.22 & 1.82 & 0.10 \\
\hline Bunch + Shoot & 3 & -139.06 & 284.24 & 1.84 & 0.09 \\
\hline Bunch + Type + Loose + Shoot $^{2}$ & 5 & -137.03 & 284.34 & 1.93 & 0.09 \\
\hline Intercept only & 1 & -145.81 & 293.63 & 11.23 & 0.00 \\
\hline
\end{tabular}

${ }^{1}$ Loose, loose oil palm fruits; Bunch, harvested fruit bunches; Palm, fruits on the oil palm; Shoot, oil palm shoots; Mature, oil palms $>3$ years of age; Immature, oil palms $<3$ years of age; Type, plantation type

${ }^{2}$ Models with an additional parameter within $\triangle \mathrm{AICc} \leq 2$ of an otherwise similar better-ranked model were not considered to be competitive despite having strong support. The extra parameter represents noise and thus does not necessarily infer biological significance.

TABLE 5 Mean \pm SD danger level ranks of wildlife species according to respondents $(n=84)$ from oil palm plantations in the Lower Kinabatangan, Sabah, Malaysia (Fig. 1), with the total number of records and the number of records in which respondents were able to rank the species.

\begin{tabular}{llll}
\hline Species & $\begin{array}{l}\text { Mean } \pm \text { SD } \\
\text { danger level rank }\end{array}$ & $\begin{array}{l}\text { Total no. } \\
\text { of records }\end{array}$ & $\begin{array}{l}\text { No. of } \\
\text { ranked } \\
\text { records }\end{array}$ \\
\hline Macaque & $1.90(0.74)$ & 14 & 10 \\
Bearded pig & $1.94(0.77)$ & 18 & 16 \\
Bornean elephant & $2.18(0.8)$ & 25 & 22 \\
Sun bear & $2.33(1.15)$ & 9 & 3 \\
Bornean orang-utan & $2.33(0.71)$ & 11 & 9 \\
Snake & $2.36(0.68)$ & 63 & 55 \\
Estuarine crocodile & $3.00(0.00)$ & 10 & 9 \\
Sunda clouded & $3.00(0.00)$ & 5 & 5 \\
leopard & & & \\
\hline
\end{tabular}

${ }^{1}$ Ranks: 1, least dangerous; 2, dangerous; 3, extremely dangerous.

${ }^{2}$ This number was used in the calculation of the mean danger level rank.

\& Chauhan, 2013; Wong et al., 2015); for example, sun bears fitted with global positioning system collars in Krau Wildlife Reserve, Peninsular Malaysia, made frequent night-time incursions into adjacent oil palm plantations (Cheah, 2013).

We presumed that oil palm plantations not only reduced the area of natural forest but also increased the mortality risk to bears. We could not discern whether bears were subject to increased mortality; however, respondents' perceptions suggest that bears are not a target of retribution. They may still be killed opportunistically but this would occur rarely, given that they are rarely seen. Mortality may also occur from bycatch: sun bears at a forest-oil palm interface in Peninsular Malaysia had a high incidence of injuries from snares set for ungulates (Cheah, 2013). We did not find evidence of this from camera-trap photographs in our study area ( $R$. Guharajan et al., unpubl. data), nor did respondents report

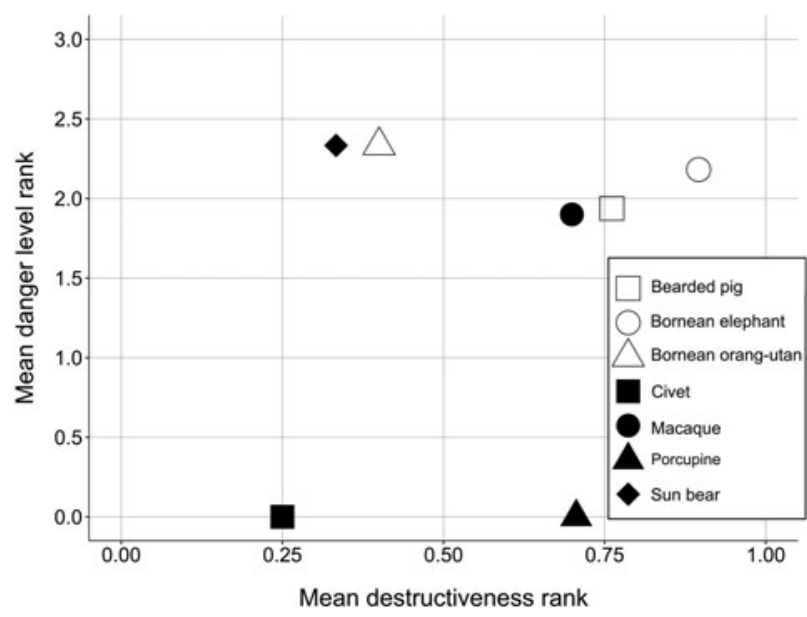

FIG. 4 Mean destructiveness and danger level ranks assigned to species by respondents from oil palm plantations in the Lower Kinabatangan, Sabah, Malaysian Borneo (Fig. 1). Civets and porcupines have a mean danger level rank of o, as no respondent reported them as being dangerous.

it. However, discoveries of butchered sun bears (L. Liman, WWF-Malaysia, pers. comm.) suggest that targeted poaching may occur, although the scale is unclear.

It is likely that sun bears benefit nutritionally from eating oil palm fruits, especially in inter-mast years when fruits are scare in the forest, and insects alone are insufficient (Wong et al., 2005; Fredriksson et al., 2006). Camera traps in our study area indicated that sun bears were in good physical condition (R. Guharajan, unpubl. data), suggesting that they were supplementing their diet from plantations. In Peninsular Malaysia, bears that routinely fed in oil palm plantations were some of the heaviest recorded from the wild (Cheah, 2013). Such feeding entails risks; however, unlike the destructive feeding of bears on other crops, sun bears can feed on oil palm fruits without causing damage. This behaviour, combined with mainly nocturnal, solitary 


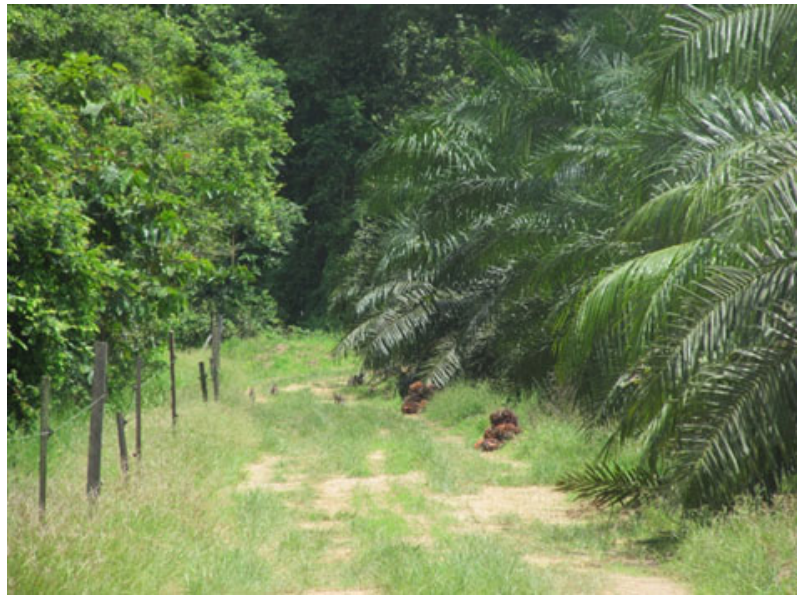

Plate 1 A typical forest-oil palm interface in the Lower Kinabatangan, Sabah, Malaysian Borneo (Fig. 1). Sun bears Helarctos malayanus can easily pass under electric fences (on the left) designed to keep elephants Elephas maximus borneensis out of plantations, and feed on the abundant loose fruits and fruit bunches on the ground.

feeding, increases the ability of sun bears to persist in this landscape. However, we do not suggest that the loss of cover and fruit and insect diversity, components of natural forest that are used and presumably needed by sun bears, is compensated for by accessing oil palm fruits.

\section{Acknowledgements}

We thank the Sabah Biodiversity Centre and Sabah Wildlife Department for their support; and Lorraine Scotson and N. Guharajan for comments on interview design. We thank all staff of FGV-Pontian United Plantations, Gomantong, Linddale and Sungai Pin estates, as well as residents of $\mathrm{Kg}$. Menggaris, Kg. Batu Putih, and $\mathrm{Kg}$. Perpaduan Datuk Moh. Funding was provided by the Association of Zoos and Aquariums, Columbus Zoo and Aquarium, Hauser Bears, the International Association for Bear Research and Management, Bell Museum of Natural History, and Wildlife Reserves Singapore.

\section{Author contributions}

RG, BG, STW and DLG conceived the project. RG and MAM collected the data. RG analysed the data. RG and DLG wrote the article, with editing by NKA and BG. SKSSN assisted with the permits.

\section{References}

Abram, N.K., Xofis, P., Tzanopoulos, J., MacMillan, D.C., Ancrenaz, M., Chung, R. et al. (2014) Synergies for improving oil palm production and forest conservation in floodplain landscapes. PLoS ONE, 9(6), e95388.
Ancrenaz, M., Oram, F., Ambu, L., Lackman, I., Ahmad, E., Elahan, H. et al. (2015) Of Pongo, palms and perceptions: a multidisciplinary assessment of Bornean orang-utans Pongo pygmaeus in an oil palm context. Oryx, 49, 465-472.

ARNOLD, T.W. (2010) Uninformative parameters and model selection using Akaike's information criterion. The Journal of Wildlife Management, 74, 1175-1178.

Augeri, D.M. (2005) On the biogeographic ecology of the Malayan sun bear. $\mathrm{PhD}$ thesis. University of Cambridge, Cambridge, UK.

Azhar, B., Lindenmayer, D.B., Wood, J., Fischer, J. \& Zakaria, M. (2014) Ecological impacts of oil palm agriculture on forest mammals in plantation estates and smallholdings. Biodiversity and Conservation, 23, 1175-1191.

Azmi, R. (1998) Natural Vegetation of the Lower Kinabatangan. Unpublished report. WWF-Malaysia and Sabah Forestry Department, Kota Kinabalu, Malaysia.

Campbell-Smith, G., Campbell-Smith, M., Singleton, I. \& Linkie, M. (2011) Apes in space: saving an imperilled orangutan population in Sumatra. PLoS ONE, 6(2), e17210.

Cheah, C.P.I. (2013) The ecology of Malayan sun bears (Helarctos malayanus) at the Krau Wildlife Reserve, Pahang, Malaysia and adjacent plantations. PhD thesis. Universiti Putra Malaysia, Selangor, Malaysia.

Estes, J.G., Othman, N., Ismail, S., Ancrenaz, M., Goossens, B., AMBU, L.N. et al. (2012) Quantity and configuration of available elephant habitat and related conservation concerns in the Lower Kinabatangan floodplain of Sabah, Malaysia. PLoS ONE, 7(10), e44601.

Fredriksson, G.M. (2005) Human-sun bear conflicts in East Kalimantan, Indonesian Borneo. Ursus, 16, 130-137.

Fredriksson, G.M., Danielsen, L.S. \& Swenson, J.E. (2007) Impacts of El Niño related drought and forest fires on sun bear fruit resources in lowland dipterocarp forest of East Borneo. Biodiversity and Conservation, 16, 1823-1838.

Fredriksson, G.M., Steinmetz, R., Wong, S. \& Garshelis, D.L. (IUCN SSC Bear Specialist Group) (2008) Helarctos malayanus. In The IUCN Red List of Threatened Species 2008: e. T9760A13014055. Http://dx.doi.org/10.2305/IUCN.UK.2008.RLTS. T9760A13014055.en [accessed 13 July 2017].

Fredriksson, G.M., Wich, S.A. \& Trisno (2006) Frugivory in sun bears (Helarctos malayanus) is linked to El Niño-related fluctuations in fruiting phenology, East Kalimantan, Indonesia. Biological Journal of the Linnean Society, 89, 489-508.

KoH, L.P. \& Wilcove, D.S. (2008) Is oil palm agriculture really destroying tropical biodiversity? Conservation Letters, $1,60-64$.

Liu, F., McShea, W.J., Garshelis, D.L., Zhu, X., Wang, D. \& SHAO, L. (2011) Human-wildlife conflicts influence attitudes but not necessarily behaviors: factors driving the poaching of bears in China. Biological Conservation, 144, 538-547.

Luskin, M.S., Christina, E.D., Kelley, L.C. \& Potts, M.D. (2014) Modern hunting practices and wild meat trade in the oil palm plantation-dominated landscapes of Sumatra, Indonesia. Human Ecology, 42, 35-45.

Marchal, V. \& Hill, C. (2009) Primate crop-raiding: a study of local perceptions in four villages in North Sumatra, Indonesia. Primate Conservation, 24, 107-116.

Meijaard, E., Buchori, D., Hadiprakarsa, Y., Utami-Atmoko, S. S., Nurcahyo, A., TuIU, A. et al. (2011) Quantifying killing of orangutans and human-orangutan conflict in Kalimantan, Indonesia. PLoS ONE, 6(11), e27491.

Nakashima, Y., Nakabayashi, M. \& Sukor, J.A. (2013) Space use, habitat selection, and day-beds of the common palm civet 
(Paradoxurus hermaphroditus) in human-modified habitats in Sabah, Borneo. Journal of Mammalogy, 94, 1169-1178.

Normua, F., Higashi, S., Аmbu, L. \& Mohamed, M. (2004) Notes on oil palm plantation use and seasonal spatial relationships of sun bears in Sabah, Malaysia. Ursus, 15, 227-231.

R Development Core Team (2015) R: A Language and Environment for Statistical Computing. R Foundation for Statistical Computing, Vienna, Austria.

Rajaratnam, R., Sunquist, M., Rajaratnam, L. \& Ambu, L. (2007) Diet and habitat selection of the leopard cat (Prionailurus bengalensis borneoensis) in an agricultural landscape in Sabah, Malaysian Borneo. Journal of Tropical Ecology, 23, 209-217.

Sabah Wildifife Department (1997) Sabah Wildife Conservation Enactment 1997. Kota Kinabalu, Sabah, Malaysia.

Sabah Wildife Department (2010) Elephant Action Plan. Kota Kinabalu, Sabah, Malaysia.

Scotson, L., Vannachomchan, K. \& Sharp, T. (2014) More valuable dead than deterred? Crop-raiding bears in Lao PDR. Wildlife Society Bulletin, 38, 783-79o.

Sethy, J. \& Chauhan, N.P.S. (2013) Human-sun bears conflict in Mizoram, North East India: impact and conservation management. International Journal of Conservation Science, 4, 317-328.

Suba, R.B., van der Ploeg, J., van't Zelfie, M. , Lau, Y.W., W Issingh, T.F., Kustiawan, W. et al. (2017) Rapid expansion of oil palm is leading to human-elephant conflicts in North Kalimantan province of Indonesia. Tropical Conservation Science, 10, https://doi. org/10.1177/1940082917703508.

U.S. Department of Agriculture, Foreign Agricultural Service (2017) Oilseeds: World Markets and Trade. Https://www. fas.usda.gov/data/oilseeds-world-markets-and-trade [accessed 13 July 2017].

Vijay, V., Pimm, S.L., Jenkins, C.N. \& Smith, S.J. (2016) The impacts of oil palm on recent deforestation and biodiversity loss. PLOS ONE, 11(7), e0159668.

Wong, S.T., Servheen, C., Ambu, L. \& Norhayati, A. (2005) Impacts of fruit production cycles on Malayan sun bears and bearded pigs in lowland tropical forest of Sabah, Malaysian Borneo. Journal of Tropical Ecology, 21, 627-639.

Wong, W.-M., Leader-Williams, N. \& Linkie, M. (2015) Managing human-sun bear conflict in Sumatran agroforest systems. Human Ecology, 43, 255-266.

WWF-Malaysia (2013) Bersatu Memerangi Pemburuan Haram (Working Together to Fight Poaching). WWF-Malaysia, Sabah, Malaysia.

Yue, S., Brodie, J.F., Zipkin, E.F. \& Bernard, H. (2015) Oil palm plantations fail to support mammal diversity. Ecological Applications, 25, 2285-2292.

\section{Biographical sketches}

Roshan Guharajan and Mohd Azzumar Magguna are interested in practical research and conservation initiatives. Nicola Ав RАм promotes effective land-use planning in oil palm-forest landscapes. Benoit Goossens studies biodiversity responses to habitat fragmentation and degradation. SIEW TE WONG works on sun bear conservation through holistic approaches. Senthilvel K.S.S. Nathan oversees wildlife management in Sabah. DAVID L. GARS HE LIS facilitates bear research and conservation worldwide. 